\title{
UMA PROPOSTA DE MODELO CONCEITUAL DE DESDOBRAMENTO DE PROCESSOS: UM ESTUDO DE CASO EM UMA ÁREA DE UMA EMPRESA INTEGRADA DE ENERGIA
}

\section{PERCEPTIONS ABOUT THE IMPLEMENTATION OF BUSINESS MANAGEMENT PROCESSES IN AN AREA OF AN INTEGRATED ENERGY COMPANY}

\author{
Aziz Khazzah El Warrak ${ }^{1}$; José Rodrigues de Farias Filho \\ ${ }^{1}$ Universidade Federal Fluminense - UFF \\ azizkwarrak@yahoo.com.br \\ ${ }^{2}$ Universidade Federal Fluminense - UFF \\ fariasfilho@gmail.com
}

\begin{abstract}
Resumo
O presente estudo tem por objetivo elaborar um modelo conceitual de desdobramento dos processos do nível 1 aos níveis 2 e 3. Para tanto, foi necessário estudar conceitos relacionados à cadeia de valor, mapeamento e desdobramento de processos. A metodologia utilizada considera uma pesquisa de natureza aplicada, pois pretende contribuir de maneira prática para solucionar um problema concreto. A abordagem é qualitativa, pois a interpretação dos fenômenos é imprescindivel para o alcance dos objetivos propostos. Quanto aos objetivos, este estudo é classificado como exploratório, uma vez que busca conhecer melhor o tema abordado. E como método de pesquisa adotou-se o estudo de caso e também a pesquisa bibliográfica. Os dados foram coletados através de documentos e observação participante e analisados através do método de construção da explanação. Os resultados obtidos nesta dissertação foram um modelo conceitual composto por cinco etapas que permite o desdobramento de processos e as percepções observadas durante sua implantação em um estudo de caso.
\end{abstract}

Palavras-chave: gestão por processos; desdobramento de processos; qualidade total.

\section{Introdução}

\subsection{A situação problema}

Um dos motivos para que os executivos não enxerguem as organizações através de processos é a dificuldade de desdobrá-los a partir do nível mais estratégico, a cadeia de valor. Smith (2007) coloca que um executivo dos anos 2000 que vem de fora da companhia demora certo tempo para conhecer os clientes e funcionários, mas leva anos para conhecer os detalhes técnicos e adquirir experiência necessária para realmente entender os processos organizacionais.

Em muitos casos, os processos de nível estratégico estão mapeados, entretanto não se consegue enxergar os processos nos níveis mais detalhados. Ou então, os processos dos níveis mais 
operacionais também estão identificados, mas falta a conexão com os processos de mais alto nível, pois os processos intermediários não foram mapeados.

Portanto, o presente estudo trata do problema de se desdobrar os processos de um nível estratégico de cadeia de valor, nível 1, aos níveis subsequentes, ainda táticos, 2 e 3. O Quadro 1 descreve de forma clara a contextualização e os problema atacado na pesquisa.

\begin{tabular}{|c|c|}
\multicolumn{2}{|c|}{ Quadro 1 - Contextualização e problema da pesquisa } \\
\hline $\begin{array}{c}\text { Os profissionais de uma empresa conhecem rapidamente sua estrutura } \\
\text { organizacional, mas demoram a conhecer como ela funciona } \\
\text { tecnicamente. }\end{array}$ & Problema \\
\hline $\begin{array}{c}\text { Os processos da cadeia de valor de uma organização, ou seja, de mais } \\
\text { alto nível, estão mapeados, mas seus subprocessos não estão } \\
\text { identificados. }\end{array}$ & $\begin{array}{c}\text { Dificuldade de desdobrar os } \\
\text { processos a partir de nível mais } \\
\text { estratégico }\end{array}$ \\
\hline $\begin{array}{c}\text { Os processos mais operacionais estão mapeados, mas falta a conexão } \\
\text { com os processos mais estratégicos. }\end{array}$ & \\
\hline
\end{tabular}

Fonte: Autoria própria, (2013)

Com o contexto e o problema identificado acima, o objetivo deste estudo é apresentar um modelo que possibilite desdobrar os processos do nível 1 nos níveis 2 e 3 . Ainda como objetivo é preciso definir as etapas necessárias para desdobrar os processos de nível $1 \mathrm{em}$ processos de níveis 2 e 3. No desdobramento, é importante definir parâmetros que direcionam os processos, como seu objetivo, insumos, produtos, fornecedores, clientes, etc.

\section{Referencial teórico}

Para desenvolver este estudo é importante conhecer os conceitos de "Cadeia de Valor" e "Desdobramento e Mapeamento de processos".

\subsection{Cadeia de valor}

O conceito de "Cadeia de Valor" foi introduzido inicialmente em Porter (1985), que o definiu como a coleção compreensiva de todas as atividades que são desempenhadas para conceber, produzir, comercializar, entregar e suportar uma linha de produto.

Segundo Santos (2007), a cadeia de valor considera todas as atividades que agregam valor aos produtos e/ou serviços até o consumidor final. Ainda nessa linha, Harmon (2007) coloca que cadeia de valor é usualmente denominada o nível 0 de processos.

Atualmente, os processos de uma cadeia de valor são classificados de três formas: processos de negócio (GONÇALVES, 2000; MELÃO e PIDD, 2000; HARMON, 2007; SANTOS, 2007), processos de suporte (MELÃO e PIDD, 2000; HARMON, 2007; SANTOS, 2007; MACKAY et al, 2008) e processos de gestão (GONÇALVES 2000; MELÃO e PIDD, 2000; HARMON, 2007; SANTOS, 2007; MACKAY et al, 2008). 
Segundo Harmon (2007), processos de negócio são aqueles que adicionam valor ao produto e/ou serviço que a organização está produzindo para seus consumidores externos. Eles geram os produtos e/ou serviços (GONÇALVES, 2000; HARMON, 2007). São os processos que caracterizam a atuação da empresa, sendo muito diferentes de uma organização para outra (GONÇALVES, 2000).

Harmon (2007) coloca que os processos de suporte são necessários para garantir que os processos de negócio continuem funcionando. Mackay et al (2008) complementam a afirmação acima, ao colocar que os processos de suporte existem para prover recursos (material ou intelectual) que suportem a criação de valor para o consumidor externo.

Para Harmon (2007), processos de gestão são focados no planejamento, organização, monitoramento e controle das atividades da organização. Melão e Pidd (2000) colocam que eles gerenciam os processos de negócio e suporte.

Este trabalho não apresenta como se define a cadeia de valor de uma organização, mas é importante conhecer esses conceitos, pois o desdobramento dos processos parte de uma cadeia de valor definida.

\subsection{Desdobramento e mapeamento de processos}

A cadeia de valor traz uma visão mais estratégica da organização, através dos processos de níveis mais altos. Entretanto, não é possível gerenciar todas as atividades olhando apenas para os processos da cadeia de valor. É necessário desdobrar os processos até o nível mais operacional, onde é possível atuar efetivamente.

O desdobramento de processos ou a decomposição funcional (BARBARÁ, 2006) consiste no detalhamento dos processos obtido pela construção de um diagrama de nível mais baixo. É a representação dos processos de nível imediatamente inferior chamado subprocessos. Estes, juntos e de forma integrada, compõem o escopo funcional do processo de nível superior ao qual estão subordinados (BARBARÁ, 2006).

A Figura 1 representa, de forma clara, a dinâmica do desdobramento de processos, facilitando a compreensão dos termos acima explicados. 


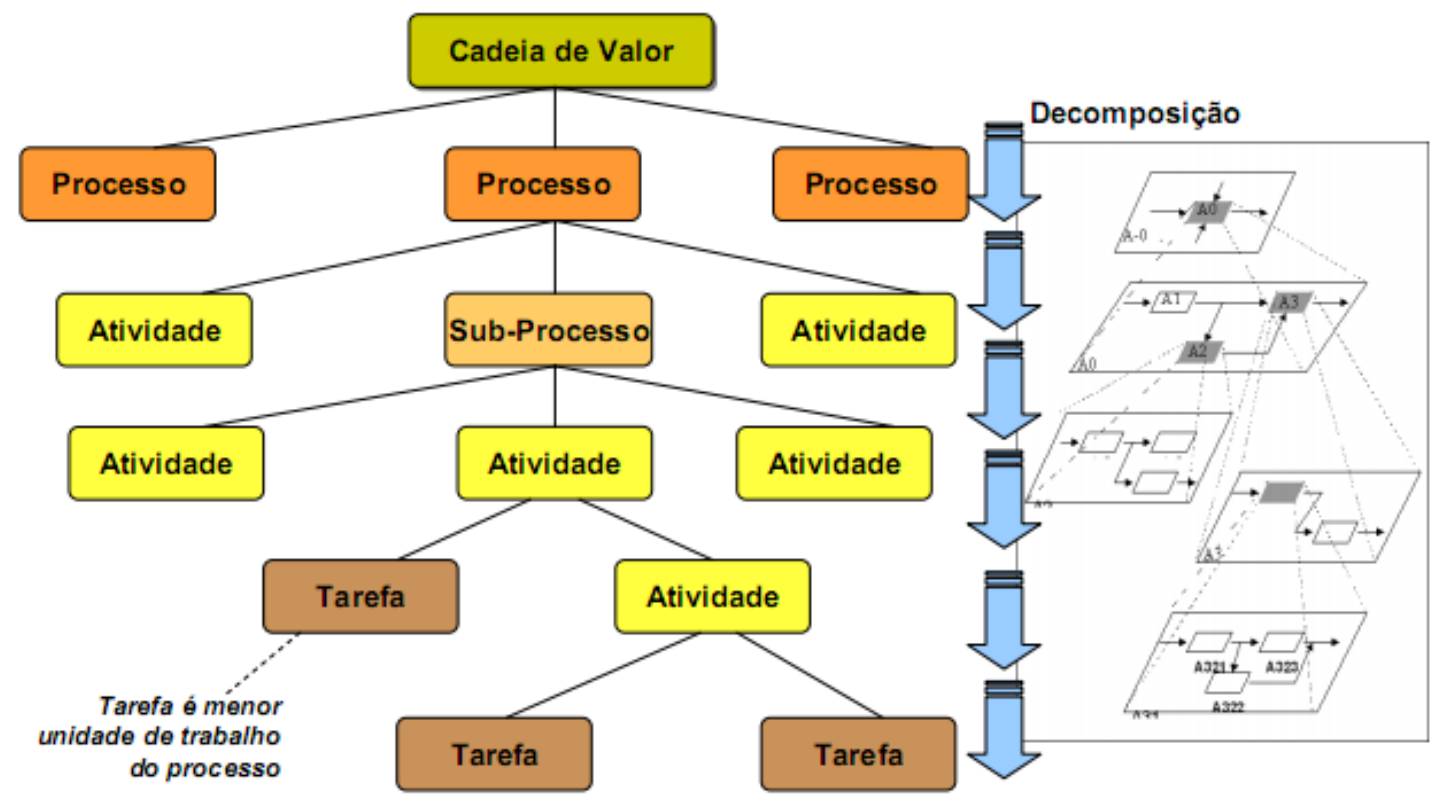

Fonte: Santos, (2007)

Segundo Santos (2007), a decomposição do processo facilita o entendimento e identificação dos seus subprocessos e/ou atividades. Para desdobrar, é necessário mapear os processos nos diversos níveis.

Para Netto (2004), o mapeamento de processos consiste na construção de um modelo que mostre os relacionamentos entre as atividades, pessoas, dados e objetos envolvidos na produção de uma especificada saída desejada. Já Maranhão e Macieira (2004) conceituam mapeamento de processos de uma organização como o conhecimento e a análise dos processos e seu relacionamento com os dados, estruturados em uma visão top-down. A palavra chave no mapeamento é o entendimento do processo.

Existe uma série de modelos e ferramentas para mapear processos, como mapa de processos, fluxograma, Integration Definition Function Modelling (IDEF0) e a matriz suppliers-inputsprocess-outputs-customers (SIPOC), que foi o modelo utilizado nesta pesquisa.

A sigla SIPOC representa a abreviação das palavras em inglês que significam fornecedores, entradas, processo, saídas e clientes respectivamente. Barbará (2006) coloca que o modelo consiste em descrever os elementos dos processos, notadamente os citados acima. A Figura 2 traz uma representação do modelo SIPOC. 


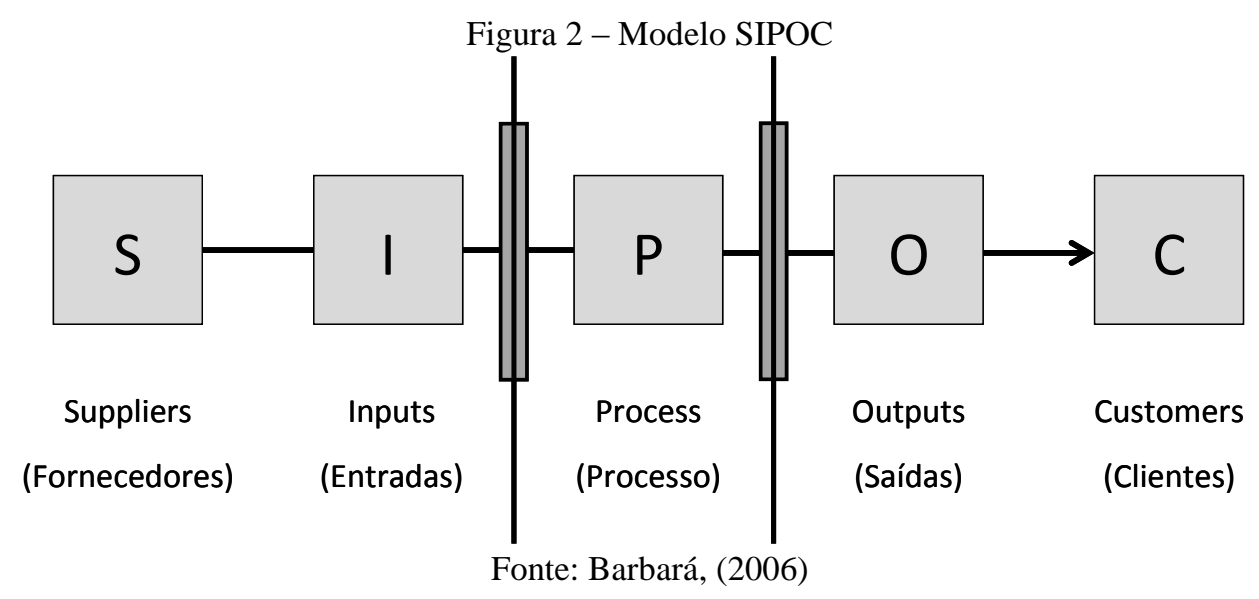

\section{Metodologia}

\subsection{Natureza, abordagem e método de pesquisa}

De acordo com o ponto de vista da sua natureza, as pesquisas podem ser classificadas como pura ou aplicada. Este estudo pode ser classificado como pesquisa aplicada, pois pretende contribuir de maneira prática para solucionar um problema concreto: a dificuldade de desdobrar os processos a partir de nível mais estratégico.

No que tange à abordagem, as pesquisas podem ser classificadas como quantitativas ou qualitativas. Esta pesquisa tem uma abordagem qualitativa, pois não há como traduzir em aspectos numéricos o que este estudo pretender abordar.

Com relação aos seus objetivos, as pesquisas também podem ser classificadas, quanto aos seus objetivos, em descritiva, explicativa ou exploratória. O presente estudo pode ser classificado como exploratório, uma vez que busca conhecer melhor o tema abordado.

As pesquisas também são classificadas de acordo com os procedimentos técnicos utilizados. Os métodos utilizados no presente estudo são a pesquisa bibliográfica e o estudo de caso, formas geralmente assumida na pesquisa exploratória.

A opção pela pesquisa bibliográfica foi feita, pois para desenvolver o desdobramento de processo, foram consultados materiais públicos e de fácil acesso principalmente os modelos e ferramentas para mapear processos.

O Quadro 2 apresenta um resumo da metodologia aplicada no estudo. 
Quadro 2 - Síntese da metodologia de pesquisa

\begin{tabular}{|l|l|}
\hline \multicolumn{1}{|c|}{ Atributo } & \multicolumn{1}{c|}{ Método } \\
\hline Natureza da Pesquisa & Pesquisa Aplicada \\
\hline Abordagem da Pesquisa & Pesquisa Qualitativa \\
\hline Objetivos da Pesquisa & Pesquisa Exploratória \\
\hline Método da Pesquisa & $\begin{array}{l}\text { Pesquisa Bibliográfica } \\
\text { Estudo de Caso }\end{array}$ \\
\hline
\end{tabular}

Fonte: Autoria própria, (2013)

\subsection{Concepção do modelo}

A etapa da revisão da literatura contribui bastante para a pesquisa, uma vez que os conhecimentos adquiridos nessa etapa foram o principal insumo para a elaboração do modelo conceitual. Cada material selecionado foi lido e resumido, identificando os principais pontos que poderiam contribuir para a proposição de um modelo que permitisse solucionar a situação problema.

As informações extraídas dos conceitos-chave estudados na pesquisa bibliográfica permitiram categorizar o modelo conceitual e estabelecer as etapas para sua implementação. No próximo tópico, o modelo conceitual e seu desenvolvimento são explorados com detalhes.

\subsection{Definição da amostra e delineamento do estudo de caso}

Uma vez pronto o modelo conceitual de desdobramento de processos, foi utilizado o método de estudo de caso para testar sua utilidade em termos práticos.

Todas as etapas do estudo de caso aparecem descritas na Figura 3.

Figura 3 - Delineamento do estudo de caso

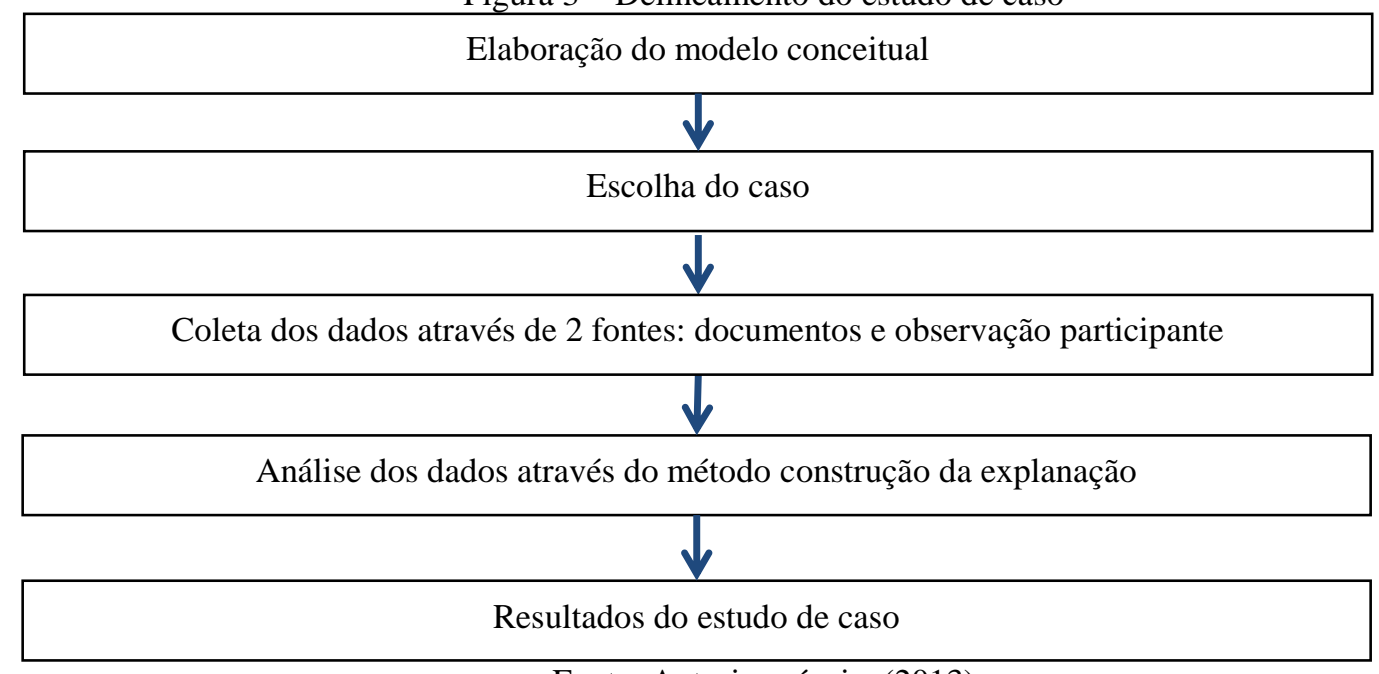

Fonte: Autoria própria, (2013)

Esse método pode englobar estudo de múltiplos casos, mas no contexto deste trabalho, foi utilizado o estudo de caso único. Essa opção se deu por ele representar um estudo de caso típico, em que a situação analisada representa uma forma comum de implantação da gestão por processos em uma organização. 
O modelo concebido foi aplicado em uma área de negócio de uma empresa do ramo de energia. O fator que contribuiu para escolha do caso foi o fato de o pesquisador estar lotado nessa área organizacional da empresa, sendo um dos responsáveis pela implantação da gestão por processos. Isso facilita bastante a aplicação do modelo, pois possibilita maior acesso às informações disponíveis - padrões, procedimentos, apresentações, fluxogramas entre outros materiais - e aos diversos atores da organização que trabalham nos processos.

\subsection{Coleta e tratamento dos dados}

Na visão de Marconi e Lakatos (2001), os dados podem ser classificados, segundo sua procedência, em primários ou secundários. Este estudo se utiliza tanto de dados primários, gerados na observação participante, como de dados secundários, ou seja, dados já processados e analisados, que foram obtidos através dos documentos disponíveis na área de aplicação do caso.

A coleta de dados, ou evidências como denominado por Yin (2005), se deu por meio de duas fontes: documentos e observação participante.

Para o desenvolvimento do caso, o pesquisador se utilizou de documentos referentes ao assunto já existentes na área estudada, como padrões, relatórios, mapas de processo, apresentações, entre outros. Havia uma quantidade considerável de materiais disponíveis.

A segunda fonte utilizada é a observação participante, em que o pesquisador deixa de ser um mero observador e passa a participar dos eventos estudados. Como o pesquisador trabalha na área estudada e faz parte da equipe que aplicou o modelo na organização, houve facilidade para ter acesso às discussões a respeito do tema. A coleta dos dados nessa fonte se deu através de reuniões, seminários, workshops e da rotina de trabalho.

Para tratamento dos dados, foi utilizado o método de construção da explanação. Segundo Yin (2005), o método de construção da explanação é utilizado quando se deseja explicar um fenômeno, normalmente relatado sobre forma de narrativa. O presente estudo descreveu todas as etapas, os meios e os envolvidos durante a implantação do modelo na área. Os dados coletados através dos documentos e observação participante foram bastante úteis na construção da explanação, pois permitiram retratar a aplicação do modelo com fidedignidade.

\section{Modelo proposto}

Ao final do desdobramento de processos espera-se obter uma representação como a apresentada esquematicamente na Figura 4. 


\section{Processo 1}

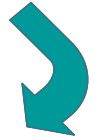

Processo 1

Nível 2

Nível 3
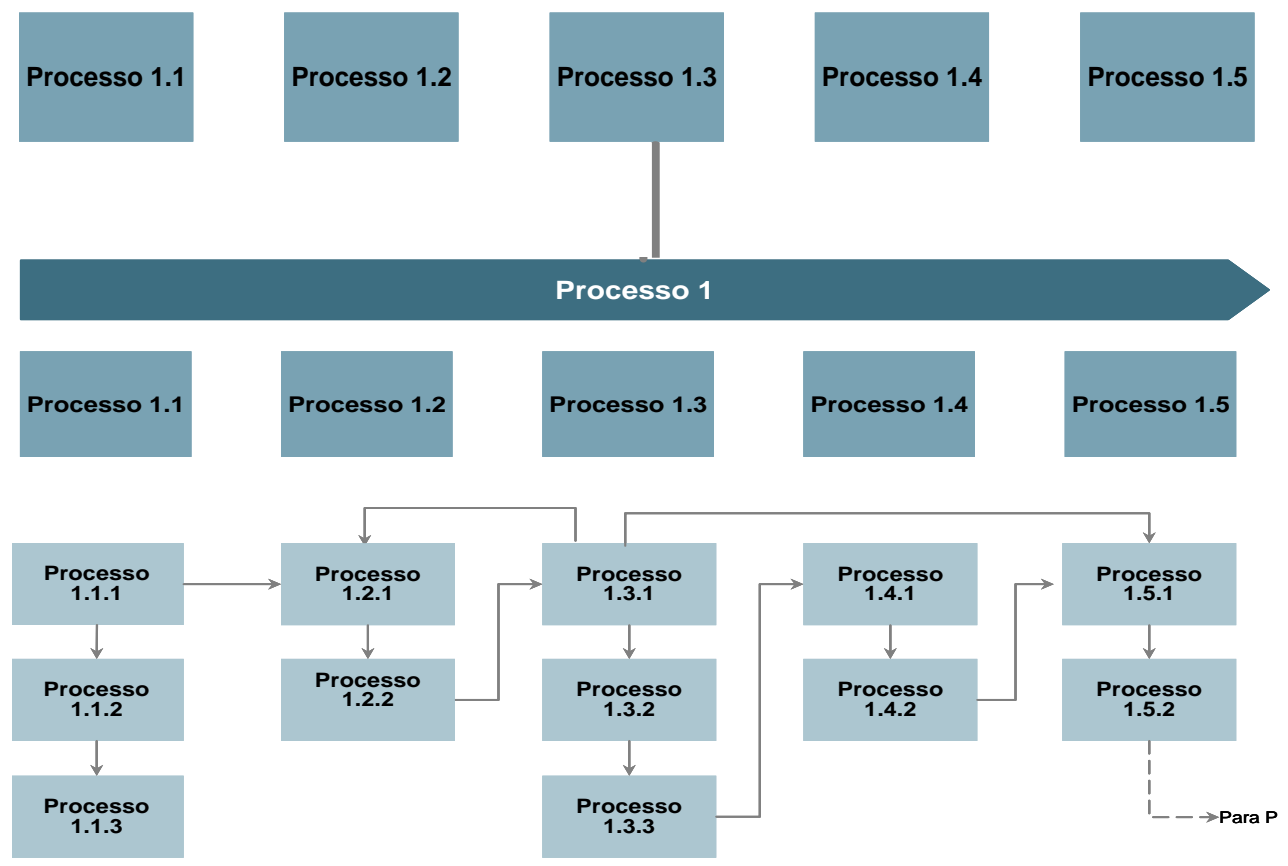

Fonte: Autoria própria, (2013)

Na figura acima, o Processo 1, é desdobrado em 5 processos de nível 2 - Processo 1.1, Processo 1.2, Processo 1.3, Processo 1.4 e Processo 1.5. Por conseguinte, cada processo de nível 2 é desdobrado em processos de nível 3.

Normalmente, as cadeias de valor das organizações possuem mais de um processo de nível 1. O exemplo acima detalha apenas um processo, mas a lógica pode ser expandida para todos os processos de nível 1 de uma organização.

A atividade de desdobramento de processos se dá a partir de uma cadeia de valor, que é composta pelos processos consolidados no mais alto nível da organização.

Portanto, antes de se iniciar qualquer atividade de desdobramento de processos, é preciso que haja uma cadeia de valor definida, validada pela alta gerência e conhecida em toda organização. Somente com esses processos de alto nível identificados é que se pode partir para um desdobramento. O modelo apresentado neste artigo pressupõe que a organização já tenha identificado sua cadeia de valor, ou seja, neste estudo não são apresentadas as atividades necessárias para uma organização estabelecer sua cadeia de valor. 
Para implementar o modelo, a figura do gestor do processo é crítica, uma vez que ele é o responsável por decompor o processo nos diversos níveis (CHANG, 2006; MARCELINO, 2007; NEUBAUER, 2009). Este artigo também não tem a finalidade de mostrar como se define os gestores de processo.

Apesar da responsabilidade por desdobrar os processos ser do gestor, é fundamental que haja um material básico e comum para todos os gestores, evitando que cada um faça de uma maneira diferente, o que dificultaria no momento da consolidação. Além disso, a presença de integrantes da equipe de processos como facilitadores do desdobramento contribui fortemente para o sucesso dessa etapa. A participação de especialistas no tema processos durante os trabalhos de desdobramento com os diversos gestores garante a uniformização entre eles e o alinhamento com os padrões definidos, principalmente aqueles relacionados aos materiais a serem utilizados.

Para elaborar o modelo propriamente dito, o primeiro passo é determinar as etapas necessárias para o desdobramento de processos. O segundo passo é definir o conjunto de materiais que devem ser utilizados para executar o desdobramento.

\subsection{Etapas do desdobramento de processos}

O modelo conceitual pode ser aplicado na decomposição em qualquer nível. As etapas que o compõem aparecem representadas na Figura 5.

Figura 5 - Etapas do modelo conceitual

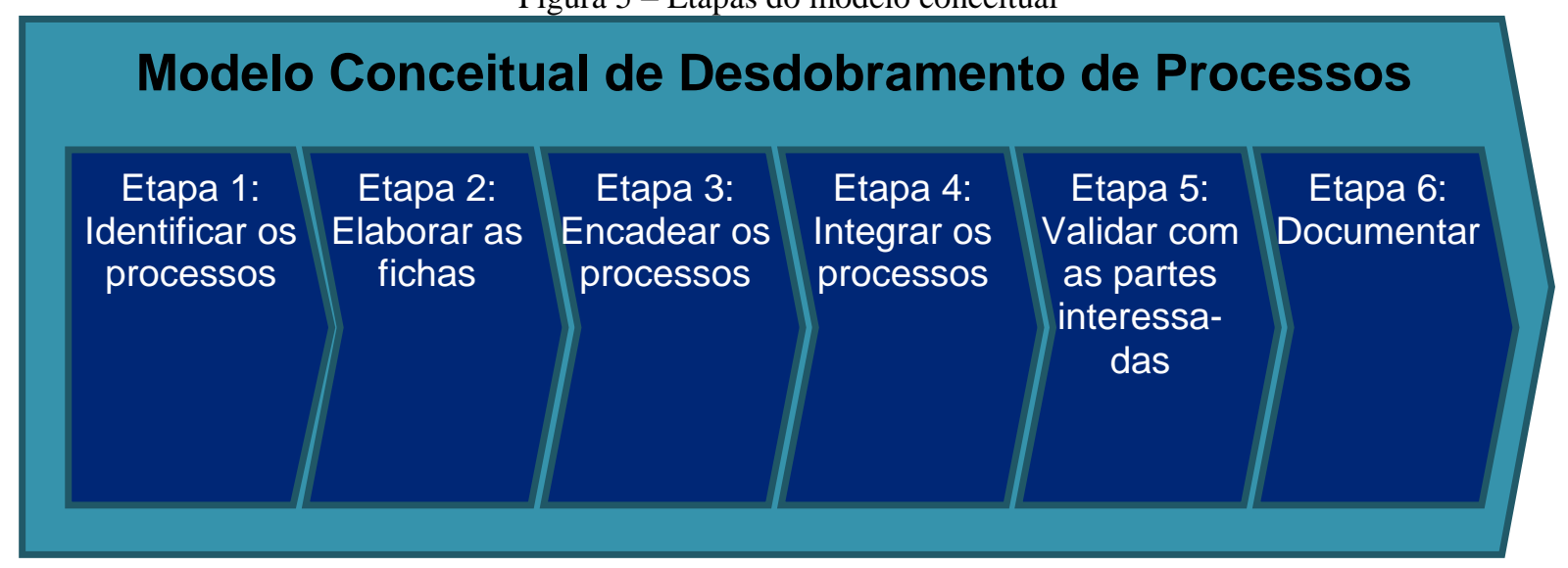

Fonte: Autoria própria, (2013)

Para facilitar a compreensão, as etapas representam o desdobramento dos processos de nível “n” em processos de nível " $n+1$ ” ou subprocessos. Cada uma dessas seis etapas é detalhada a seguir:

1) Identificação dos processos de nível "n+1" - esta etapa é desenvolvida individualmente para cada processo de nível " $n$ " e consiste apenas no levantamento dos principais subprocessos que são derivados do processo do nível acima. O produto esperado desta fase é a listagem dos processos de nível " $n+1$ ” que compõem o processo " $n$ ” em questão. 
2) Elaboração das fichas dos processos de nível "n" e de nível "n+1" - nesta etapa são levantadas algumas das principais informações de cada processo, como seu objetivo, insumos, entregas. Os campos necessários para o preenchimento dessas informações devem constar em uma ficha padrão, conforme proposta a ser mostrada no próximo subtópico. Esta etapa também é realizada individualmente para cada processo e o produto esperado são as fichas preenchidas.

3) Encadeamento dos processos de nível " $n+1$ " - com processos de nível " $n+1$ " definidos e suas informações mapeadas conforme etapa anterior, o terceiro passo é identificar o relacionamento entre esses processos do nível abaixo e traçar as setas de ligação entre eles. Cabe lembrar que esta etapa ainda é feita individualmente para cada processo e o produto esperado é o fluxo dos processos do nível " $\mathrm{n}+1$ ".

4) Integração entre os processos de nível "n” - esta etapa é realizada com a participação de todos os gestores conjuntamente. A partir do que foi desenvolvido para cada processo, pretendese expandir a construção dos fluxos de processo e criar uma visão sistêmica. Os objetivos são validar as interfaces entre os processos de nível " $n$ " mapeadas nas etapas anteriores e produzir um fluxo integrado.

5) Validação com as partes interessadas - esta etapa consiste em apresentar o material para outras áreas que de alguma forma estão envolvidas com esses processos. Espera-se, no final desta etapa, que os fluxos e as informações geradas estejam validados por todas as partes interessadas.

6) Documentação - a última etapa prevê que todo material produzido seja transformado em padrões, documentado, catalogado e armazenado em bancos de dados onde todos os interessados tenham acesso. Além disso, é importante que haja divulgação e disseminação desse material para estimular sua utilização, evitando que ele fique restrito a quem conduziu os trabalhos.

\subsection{Material para o desdobramento de processos}

Para que o trabalho seja desenvolvido de maneira uniforme entre os diversos processos a serem desdobrados, é fundamental que todos os gestores utilizem um material único.

Dentre as etapas apresentadas no subtópico anterior, a elaboração das fichas dos processos de nível " $n$ " e de nível " $n+1$ " requer um formato padrão. Para validar com as partes interessadas também é necessária uma uniformização, uma vez que o resultado do desdobramento é levado para atores diversos.

A construção da ficha básica foi feita a partir da matriz SIPOC, apresentada no subtópico 2.2. Ela contém os seguintes campos: 
- Objetivo: descreve a finalidade do processo, sua razão de ser. O preenchimento desse campo é muito importante, uma vez que contribui para a identificação posterior dos indicadores de processo;

- Descrição: apresenta os subprocessos relacionados ao processo cujas informações estão sendo levantadas;

- Insumos / fornecedores: explicitam os bens, serviços ou informações que são necessários para a execução do processo, bem como o processo que fornece o insumo;

- Produtos / clientes: explicitam os bens, serviços ou informações que são produzidos pelo processo e a destinação de cada um deles.

A Figura 6 apresenta a ficha de processo.

Figura 6 - Padrão de ficha de processo

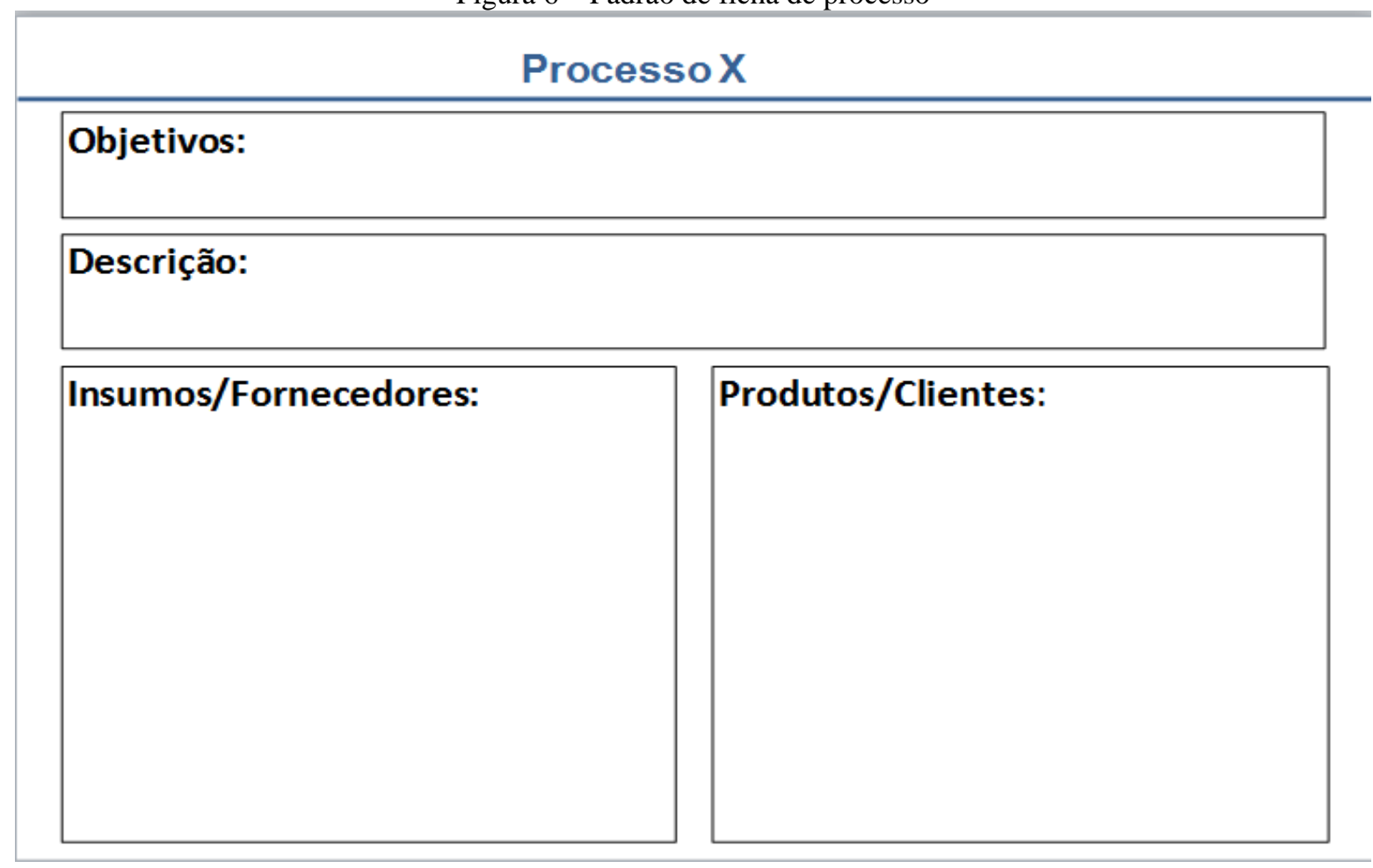

Fonte: Autoria própria, (2013), em conjunto com Paulo Henrique Costacurta et al

Com relação à validação com as partes interessadas, o primeiro passo é levantar todos os atores que de alguma forma impactam ou são impactadas pelo desdobramento. Posteriormente, deve-se definir a maneira como o desdobramento será validado por cada uma das partes interessadas, estipulando o prazo. Pode ser através de reuniões, envio de e-mail, entrega de documentação entre outras formas. Com essas definições, a equipe de processos acompanha a situação e registra as observações. No fim, a equipe consolida todos os comentários pertinentes e propõe alterações no desdobramento que havia sido feito inicialmente. Essas alterações devem ser revalidadas com todos os envolvidos, principalmente com os gestores de processos. O Quadro 3 traz um exemplo de padrão para validação das partes interessadas. 
Quadro 3 - Padrão de validação com as partes interessadas

\begin{tabular}{|l|l|l|l|l|}
\hline Parte Interessada & \multicolumn{1}{|c|}{ Como Validar } & \multicolumn{1}{|c|}{ Quando } & \multicolumn{1}{c|}{ Status } & \multicolumn{1}{c|}{ Observações } \\
\hline Patrocinador & Através de Reunião & em 12/05/2011 & Reunião realizada & $\begin{array}{l}\text { Sugestão de excluir o processo 1.2 e } \\
\text { incluir o processo xyx como 1.6 }\end{array}$ \\
\hline Unidade A & $\begin{array}{l}\text { Envio de email com } \\
\text { arquivo }\end{array}$ & $\begin{array}{l}\text { responder até } \\
10 / 05 / 2011\end{array}$ & $\begin{array}{l}\text { Email respondido em } \\
11 / 05 / 2011\end{array}$ & Não há nenhum comentário \\
\hline $\begin{array}{l}\text { Tecnologia da } \\
\text { Informação }\end{array}$ & $\begin{array}{l}\text { Entrega dos } \\
\text { documentos }\end{array}$ & $\begin{array}{l}\text { responder até } \\
10 / 05 / 2011\end{array}$ & $\begin{array}{l}\text { Comentários enviados } \\
\text { por email em 09/05/2011 }\end{array}$ & $\begin{array}{l}\text { Identificou algumas dificuldades } \\
\text { sistema corporativo de mapeamento }\end{array}$ \\
\hline & & & & \\
\hline
\end{tabular}

Fonte: Autoria própria, (2013)

\section{Estudo de caso}

Esta seção tem por objetivo apresentar o caso em que o modelo conceitual foi testado. Por questões de confidencialidade, o nome da empresa não pôde ser revelado. Desta maneira, neste capítulo são abordadas algumas informações genéricas da organização de forma a caracterizá-la.

A aplicação do modelo conceitual se deu em uma área de uma empresa integrada de energia. A empresa está presente em todos os continentes e é considerada uma das dez maiores do mundo no seu ramo. Ela atua em praticamente todos os elos da cadeia, desde a descoberta do petróleo e gás natural até a comercialização dos produtos finais, trabalhando também com diversas fontes alternativas de energia como biocombustíveis, eólica, entre outras. Assim como a maioria das grandes corporações do setor, a empresa possui atividades tanto em terra como no mar. Alguns números da empresa ao final do exercício de 2010 seguem abaixo:

- Valor de mercado acima de US\$ 100 bilhões;

- Receita operacional e lucro operacional superiores a US\$ 120 bilhões e a US\$ 20 bilhões respectivamente;

- Investimentos acima de US\$ 15 bilhões;

- Produção de petróleo e gás maior do que 2 milhões de barris de óleo equivalente por dia;

- Venda de Derivados acima de 3 milhões de barris por dia; 
- Reservas Provadas superando a marca de 8 bilhões de barris de óleo equivalente;

- Número de funcionários superior a 50 mil.

O modelo foi aplicado em uma das maiores áreas de negócio da empresa, responsável por boa parte dos resultados econômicos e operacionais e dos investimentos da organização para os próximos anos, de acordo com seu plano de negócios divulgado recentemente.

\section{Análise de resultados}

Este tópico mostra como o modelo conceitual foi implantado, com os documentos utilizados, período de aplicação, pessoas envolvidas, as principais percepções, enfim mostra como se desenvolveu a aplicação do modelo no caso.

A área do estudo de caso já havia definido sua cadeia de valor e os gestores para seus processos até nível 2. Espelhando a cadeia de valor da empresa, a área detalhou, no nível mais macro, apenas os processos de negócio, mantendo os processos de gestão e os processos de suporte consolidados. A área contém três processos de negócio no nível 1 que ocorrem de maneira sequencial.

As discussões que ocorreram durante a elaboração da cadeia de valor já contribuíam para a construção de uma visão inicial de desdobramento do nível 2 de processos e a definição dos gestores.

O desdobramento de processos até o $3^{\circ}$ nível, que teve início em janeiro de 2011 e se estendeu até abril do mesmo ano, foi realizado com apoio de uma consultoria especializada.

Nessa etapa, alguns documentos já existentes foram utilizados. O principal direcionador, não só para o desdobramento de processos como para todos os trabalhos de gestão por processos da área, foi o padrão de gestão de processos da companhia, que sofreu pequenas adaptações para facilitar sua aplicação.

Outro importante documento utilizado durante todas as etapas da iniciativa foi o glossário, em que aparecem as definições para os termos relacionados ao assunto "processo". Sempre que havia dúvidas durante as discussões, o glossário era consultado e ajudava a esclarecer as questões.

Para esse trabalho, os gestores designaram representantes técnicos para contribuírem no desenvolvimento das atividades. A equipe corporativa de processos coordenou de forma geral os trabalhos, acompanhando o desenvolvimento das atividades por cada gestor para garantir a uniformidade e aderência às metodologias definida e aos conceitos.

Com os técnicos indicados, a consultoria envolvida e a equipe de processo na coordenação, se pôde elaborar um cronograma para essa primeira fase, cujo objetivo era revisar os processos de 
nível 2 concebidos preliminarmente durante a concepção da cadeia de valor e desdobrá-los num terceiro nível.

A primeira decisão com relação ao método de trabalho e ao cronograma foi dividir os participantes em grupos de acordo com os processos e incluir um representante da equipe de processos em cada grupo. Outra importante decisão foi fixar um dia da semana e horário para que cada grupo se reunisse rotineiramente. Por exemplo, todos os envolvidos no processo 1.1 de segundo nível reservaram, em suas agendas, a terça-feira pela manhã para as reuniões do grupo entre Janeiro de 2011 e Abril de 2011.

A área onde foi aplicado o estudo tem uma cultura forte de padronização. Dessa forma, antes de iniciar as reuniões com os grupos, foram levantados os materiais já existentes que poderiam auxiliar nos trabalhos. Alguns fluxos de processo e padrões foram identificados e muitos documentos foram aproveitados.

Nas reuniões de cada grupo, para desdobrar os processos, foi utilizada a ficha padrão de processo apresentada na Figura 6. Foram necessárias de 4 a 6 reuniões com os grupos para gerar uma visão individual do processo trabalhado pelo grupo. A variação na quantidade de reuniões se deu devido aos diferentes graus de complexidade entre os processos e aos diferentes níveis de familiaridade dos técnicos com o tema "processos". Cada grupo concluiu as etapas 1, 2 e 3 sinalizadas no subtópico 4.1 .

Após ser construída a visão individualizada pelos técnicos, os gestores discutiram os processos, buscando a integração entre eles. Foram necessárias 2 reuniões para realizar essa atividade que corresponde à etapa 4 sinalizada no subtópico 4.1 .

Os processos aprovados pelos gestores, com seus fluxos desenhados foram submetidos à validação das demais partes interessadas. Foram realizados dois seminários com essa finalidade: um para discussão do desdobramento a partir do processo 1 e outro para discutir conjuntamente os processos 2 e 3, já que o público era basicamente o mesmo. Esses seminários fazem parte das atividades necessárias para concluir a etapa 5 do subtópico 4.1 .

Por fim, todos os materiais gerados foram documentados e disponibilizados para a força de trabalho, conforme orienta a etapa 6 do subtópico 4.1 .

No fim do desdobramento, chegou-se aos processos de Nível 2 e seus respectivos gestores. A Figura 7 apresenta, como exemplo, o desdobramento do Processo 1. 
Figura 7 - Processo 1: desdobramento no segundo nível e seus gestores

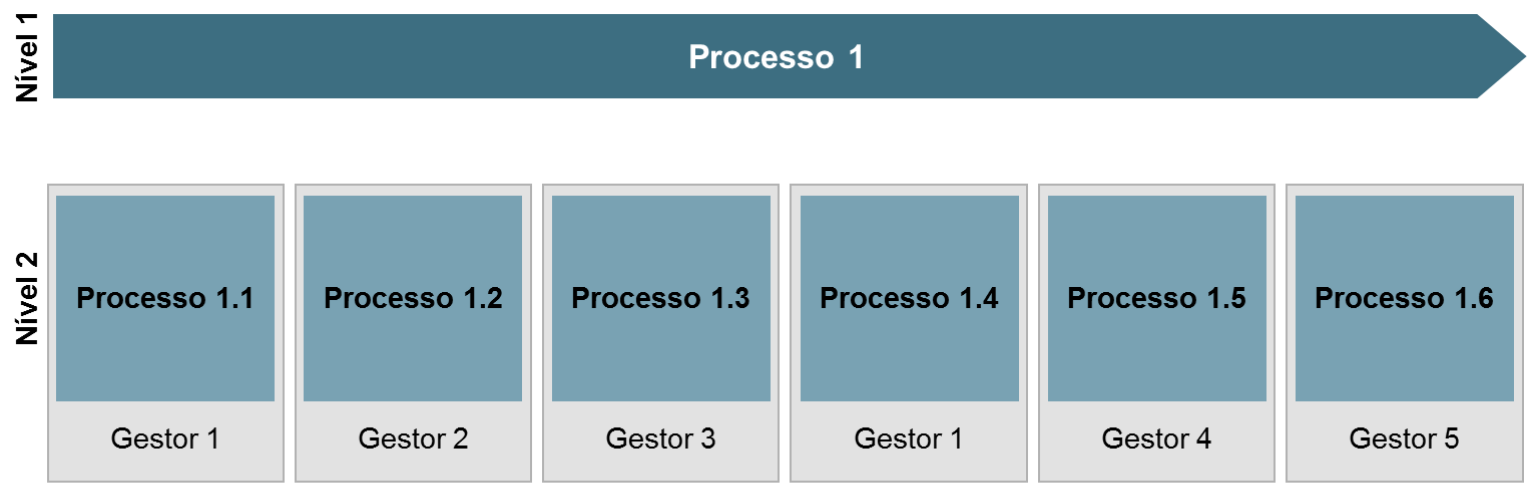

Gestores dos Processos

Fonte: Autoria própria. Exemplo do desdobramento do processo 1 adaptado da versão elaborada pelo autor em conjunto com Paulo Henrique Costacurta et al (2013).

Após a explanação de como o modelo conceitual foi aplicado no estudo de caso é necessário refletir sobre alguns pontos observados que não se referem a nenhuma etapa específica, mas da implantação do modelo de modo geral.

O primeiro ponto a ser mencionado é que em alguns momentos foi necessário abrir mão da aplicação integral dos conceitos estudados na literatura para que fosse possível dar continuidade ao que estava sendo desenvolvido. Nem todos os envolvidos, principalmente os gerentes de mais alto nível que tomam as decisões que direcionam os trabalhos, conhecem os conceitos corretamente. Como o desenvolvimento das atividades depende do comprometimento desses envolvidos, em alguns casos foram feitas concessões, normalmente demandadas por áreas que respondem por grande parte do resultado da organização e por isso possuem força na relação de poder. Era preferível fazer certas concessões e ter essas áreas como aliadas do que ser inflexível com relação aos conceitos e não conseguir avançar por conta disso. Quando essas áreas passaram a caminhar alinhadas com o propósito do trabalho, as dificuldades diminuíam e as atividades eram desenvolvidas mais rapidamente.

O forte patrocínio também merece ser destacado. O diretor, figura máxima na cadeia de comando, se empenhou pessoalmente para ver a gestão por processos rodar na organização. A área corporativa, responsável por todas as etapas de sua implementação, inclusive o desdobramento de processos, e a área gestora dos processos 2 e 3, também se comprometeram fortemente para que isso fosse possível.

Se por um lado, o patrocínio é altamente positivo, por outro, inspira certos cuidados. Os patrocinadores precisam conhecer bem o tema, devem estar bem alinhados com o propósito, senão acabam direcionando as ações para outros caminhos.

A demanda de gestão por processos na organização veio muito forte, pressionando para que ações fossem feitas. Apesar de haver um plano de implantação, com atividades e cronogramas 
definidos, a ansiedade por fazer rodar, principalmente no início, atropelou esse plano e em alguns momentos acabou atrapalhando a sistematização da gestão por processos.

As reuniões com os patrocinadores também devem ser apontadas como questões importantes a serem relatadas. Sempre que havia alguma indefinição ou quando era necessário um evento que marcasse o encerramento de alguma atividade relevante dos trabalhos, convocava-se uma reunião com a presença de pelo menos um dos patrocinadores. Essa estratégia se mostrou acertada, pois além de definir pontos pendentes, aumentava o conhecimento de todos no assunto e criava comprometimento, principalmente da alta administração, na implantação do modelo.

A cultura organizacional também foi bastante influente na aplicação do modelo conceitual. Um exemplo disso é que em alguns momentos os trabalhos não avançavam como esperado, pois não se respeitou a cultura da organização de construir tudo aos poucos e em conjunto com todos os participantes. Isso fez com que os envolvidos apresentassem resistência em certos momentos.

\section{Conclusões}

Esta seção finaliza o estudo apresentando o que foi desenvolvido ao longo dos trabalhos e sua relação com o objetivo da pesquisa.

O objetivo do estudo - apresentar um modelo que possibilite desdobrar os processos do nível 1 nos níveis 2 e 3 - foi alcançado. Essa afirmação pode ser feita, uma vez que um modelo conceitual foi elaborado (tópico 4) e testado em um estudo de caso (tópico 5 e tópico 6).

O modelo de desdobramento de processos é composto por seis etapas - 1) Identificar os processos; 2) Elaborar as fichas dos processos; 3) Encadear os processos; 4) Integrar os processos; 5) Validar com as partes interessadas e 6) Documentar - e dois materiais de apoio: Padrão de Ficha de Processo e Padrão de Validação com as Partes Interessadas.

Ele foi aplicado sem maiores dificuldades em uma área de uma empresa de energia. Após sua utilização no estudo de caso, algumas observações podem ser feitas.

A utilização de documentos já existentes na organização, como padrões e fluxogramas, facilita bastante o desdobramento. Além disso, é importante respeitar a cultura organizacional para que a implantação ocorra minimizando a possível resistência por parte da força de trabalho.

Um planejamento claro e consistente para execução das etapas também contribui para que o desdobramento dos processos seja feito de maneira mais precisa. A utilização de material padronizado de apoio também aumentam as chances de sucesso.

Em alguns momentos é preciso abrir mão de aplicar os conceitos integralmente, principalmente quando envolve pessoas influentes na organização. É preferível fazer certas concessões e ter essas pessoas como aliadas do que ser inflexível com relação aos conceitos e não conseguir avançar por conta disso. 
O patrocínio da alta administração, bem como a existência de uma equipe dedicada se mostrou fundamentais para conseguir evoluir no desenvolvimento dos trabalhos.

Como mensagem final, pode-se dizer que o modelo de desdobramento de processos apresentado neste artigo pode ser aplicado largamente do modelo respeitando as especificidades de cada organização, aproveitando o que já foi produzido internamente e procurando o engajamento da alta administração e de pessoas formadoras de opinião.

\section{Abstract}

This study aims to develop a conceptual model of processes deployment from level 1 to levels 2 and 3. For that, it was necessary to study concepts related to value chain, processes mapping and deployment. The methodology considers a research of an applied nature, because it aims to contribute in a practical way to solve a concrete problem. The approach used is qualitative, because the interpretation of the phenomena is essential for achieving the goals. About the goals, this study is classified as exploratory, because it seeks to better understand the topic discussed. And the research methods adopted was a case study and bibliography research. Data were collected through documents and participant observation and analyzed by the method of qualitative content analysis. The results obtained in this work were a conceptual model consists of five steps that allows the deployment of processes and perceptions observed during their deployment in a case study.

Key-words: business process management; process deployment; total quality.

\section{Referências}

BARBARÁ, S. Gestão por processos: fundamentos, técnicas e modelos de implementação. São Paulo: Qualitymark, 2006.

CHANG, J. Business process management systems: strategy and implementation. [S.1.]: Auerbach Publications, 2006.

GONÇALVES, J. E. L. As Empresas são grandes coleções de processos. Revista de Administração de Empresas, [S.1.], p. 6-19, 2000.

HARMON, P. Business process change: a guide for business managers and BPM and six sigma professionals. 2nd. ed. [S.1.]: Elsevier, 2007.

MACKAY, D. et al. Delivering sustained performance through a structured business process approach to management. Measuring Business Excellence, [S.1.], v. 12, no. 4, p. 22-37, 2008.

MARANHÃO, M.; MACIEIRA, M. E. B. O processo nosso de cada dia: modelagem de processos de trabalho. [S.l.: s.n.], 2004.

MARCELINO, L. R. Sistema de gestão orientada por processos SGOPP: uma proposta de um sistema de gestão OPP sistêmico e sua metodologia de implantação. Florianópolis: Universidade Federal de Santa Catarina, 2007.

MARCONI, M. A.; LAKATOS, E. M. Metodologia do trabalho científico: procedimentos básicos, pesquisa bibliográfica, projeto e relatório, publicações e trabalhos científicos. 6. ed. São Paulo: Atlas, 2001.

MELÃO, N; PIDD, M. A conceptual framework for understanding business processes and business process modeling. Info Systems Journal, [S.1.], v. 10, p. 105-129, 2000.

NETTO, C. Proposta de modelo de mapeamento e gestão por macroprocessos. Tese (Doutorado) - Escola Politécnica, Universidade de São Paulo, São Paulo, 2004. 
NEUBAUER, T. An empirical study about status of business process management. Business Process Management Journal, [S.1.], v. 15, no. 2, p. 166-183, 2009.

PORTER, M. E. Vantagem competitiva: criando e sustentando um desempenho superior. Rio de Janeiro: Campus, 1985 .

SANTOS, R. Gestão por processos: as melhores práticas para gestão por processos. [S.1.: s.n.], 2007. Slides.

SMITH, R. Business process management and balanced scorecard. [S.1.]: Wiley, 2007.

YIN, R. K. Estudo de caso: planejamento e métodos. 3. ed. São Paulo: Bookman Companhia, 2005.

\section{Dados dos autores}

Nome completo: Aziz Khazzah El Warrak

Filiação institucional: Universidade Federal Fluminense - UFF

Endereço completo para correspondência: Rua José Peixoto, 291, Centro, São João de Meriti, RJ, CEP: $25520-430$

Telefone para contato: (21) 8871-5074

e-mail: azizkwarrak@yahoo.com.br

Nome completo: José Rodrigues de Farias Filho

Filiação institucional: Universidade Federal Fluminense - UFF

Endereço completo para correspondência: - Rua Passo da Pátria, 156, sala 330 - São Domingos, Niterói - RJ, CEP: 24210-240

Telefone para contato: (21) 9944-6270

e-mail: fariasfilho@gmail.com

Submetido em: 30/06/2013

Aceito em: 08/10/2014 